\title{
Parâmetros de projeto (patterns) de Christopher Alexander traduzidos para o português*
}

\author{
Danila Martins de Alencar Battaus \\ Arquiteta e urbanista, pós-doutoranda pelo IAU-USP, \\ Avenida Trabalhador Sancarlense, 400, Centro, São Carlos, SP, \\ CEP 13566-590, (16) 3373-9800, dmalencar@hotmail.com
}

\begin{abstract}
* Resenha do livro de Christopher Alexander, traduzido por Alexandre Salvaterra: Uma Linguagem de Padrões: A Pattern Language (Porto Alegre, Editora Bookman, 2013).

1 HOLMSTAD, O. (2012). "The Man who started a Fire (Christopher Alexander Lecture at Berkeley, California)", 11 de setembro de 2012, disponivel em "permaculturenews.org", acessado em $11 / 02 / 2013$
\end{abstract}

hristopher Alexander, arquiteto nascido em Viena (1936), mudou-se para a Inglaterra (1938) e cresceu em território britânico, onde se formou Matemático e Arquiteto. Em meados do século XX (1958), buscou aprofundar seus conhecimentos, nos Estados Unidos. Iniciou sua trajetória na América especializando-se em Harvard, porém, as formulações de suas principais teorias e a consolidação de sua prática profissional se deram na Califórnia, precisamente em Berkeley, como professor - hoje, Emérito - da Universidade da Califórnia. Também naquela cidade fundou, em 1967, o CES - Center for Environmental Structure, uma organização composta por profissionais que constituíram as equipes de trabalho de Alexander em inúmeros projetos e na autoria de obras literárias, como foi o caso do livro "A Pattern Language", publicado em 1977, com Sara Ishikawa e Murray Silverstein, entre outros colaboradores.

No período compreendido entre o final dos anos de 1960 e 1973, segundo obra "Christopher Alexander: the search for a new paradigm in Architecture" de Stephen Grabow (1983) e que constitui a biografia do arquiteto, Alexander ocupou-se com a produção do livro "A Pattern Language" e de outras obras conjugadas: "The Oregon Experiment" (1975) e "The Timeless Way of Building" (1979), período este, em que o CES - Center for Environmental Structure consistia em um pequeno grupo de profissionais, entre eles, Sara Ishikawa e Murray Silverstein, co-autores de "A Pattern Language". Nos anos seguintes (1973 a 1976), na iminência de publicar o referido livro, Christopher Alexander dedicou-se a experiências com materiais de construção em projetos no exterior como, por exemplo, uma proposta de habitação social na França.
Não obstante a pequena incursão das ideias de Alexander na mídia e sua popularidade, na época, como menciona Oyving Holmstad ${ }^{1}$ ao salientar o fato de "A Pattern Language" ter sido um best-sellerentre os livros de Arquitetura, seus projetos repercutiram no continente europeu. Por conseguinte, a renomada historiadora e teórica do urbanismo Françoise Choay, respondia pela edição e tradução de suas obras bibliográficas para o francês, junto à Oxford University Press daquele país.

Neste sentido, o projeto na França, iniciado por Choay, foi desenvolvido por Alexander, o que representou a oportunidade de sintetizar quase todas as ideias formuladas por ele naquele período, permitindo simulações de projeto. Envolvida com a temática das habitações populares francesas na época, Françoise Choay o indicou para explorar novas alternativas de construção com qualidade. Alexander, portanto, buscou empreender o projeto a partir de seus preceitos, tais quais: a autogestão e orientação pelos usuários, as vizinhanças, financiamentos, o "arquiteto-construtor" e o modelo de um processo dinâmico de construção. A propósito, CHOAY (1980) observa em sua obra "A Regra e o Modelo" a presença da utopia como força presente nos pressupostos de Alexander e afirma que o arquiteto "coloca-se como libertador dos usuários graças a princípios (patterns) que têm por objeto permitir-lhes exprimir seus desejos no processo de elaboração do quadro construído". (p. 296)

Originalmente, o livro "A Pattern Language" foi publicado em inglês, pela editora Oxford University Press (1977) e, no ano de 1980, teve sua tradução para o idioma espanhol pela editora Gustavo Gili. Poucos anos depois, em 1982, o livro foi traduzido 


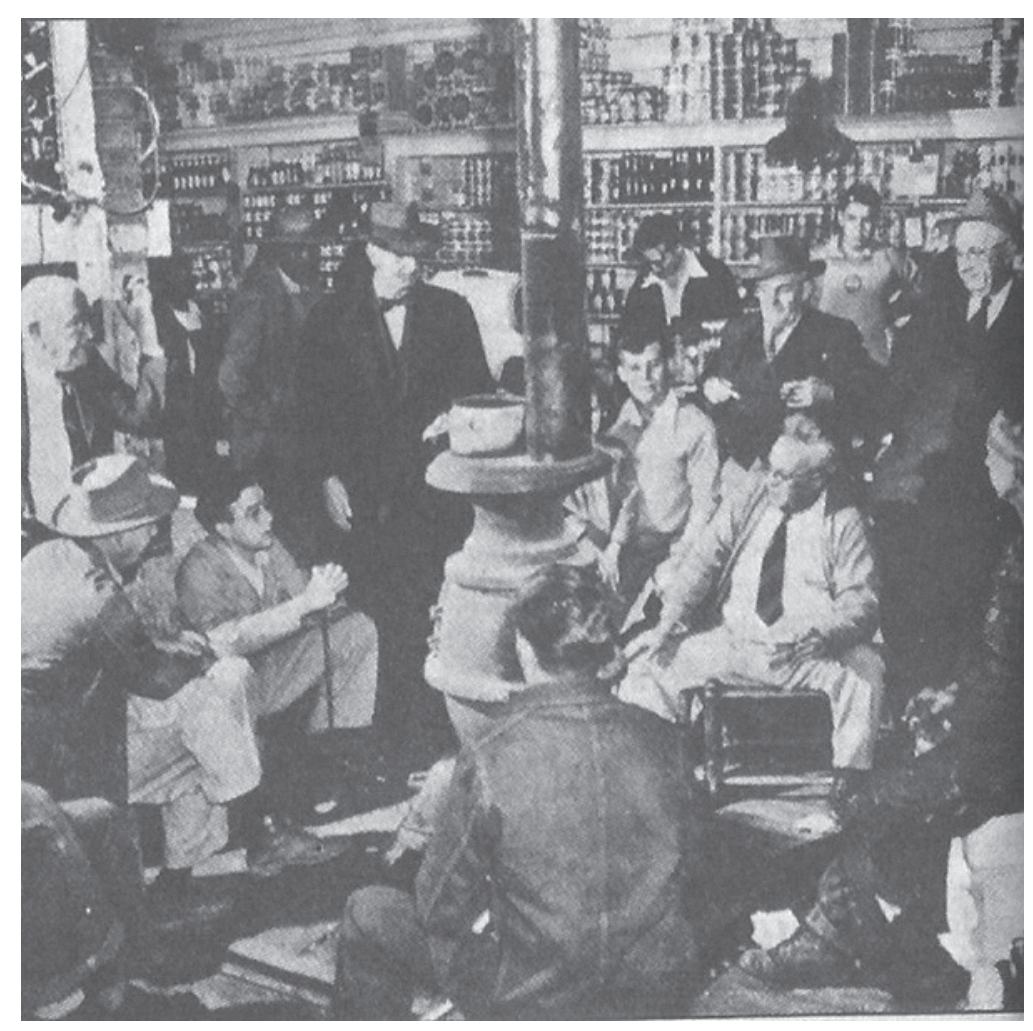

Figura 1: "Bairro Identificável", ilustrado por Alexander como o "padrão 14" no livro "A Pattern Language" (1977). Fonte: SALVATERRA 2013, p. 80. para o alemão e, no ano de 1984, para o japonês (Kajima Institute Publishing Co. Ltd.), pois Alexander e sua equipe engendravam, na época, um de seus processos participativos na implantação de um novo campus universitário, nas imediações de Tóquio. Décadas à frente, no ano de 2013, estudiosos e difusores da produção de Christopher Alexander contam com a versão de "A Pattern Language" em português: "Uma Linguagem de Padrões: a pattern language", com tradução de Alexandre Salvaterra e consultoria, supervisão e revisão técnica de Doris Catharine Cornelie Knatz Kowaltowski e Raquel Regina Martini Paula Barros.

A Linguagem de Padrões constitui-se uma compilação de parâmetros projetuais estabelecidos pelo arquiteto e sua equipe, com o intuito principal de auxiliar a interlocução entre profissionais e usuários de edificações e empreendimentos urbanísticos, em processos participativos. Esta prática do envolvimento de ambos nos processos de projeto e construção representa o principal legado de Christopher Alexander. Seu currículo contém inúmeros processos nos quais esta linguagem foi incorporada, ao longo de sua trajetória profissional em diferentes países, entre outros: Estados Unidos, Japão, Peru, México e Venezuela.

A narrativa sobre esses processos foi conteúdo de alguns de seus livros como "The Production of Houses" que relata o projeto de Alexander para Mexicali (México) e, também recentemente, o uso da Linguagem de Padrões na concepção e construção de um campus universitário no Japão (Eishin) foi publicado no livro "The Battle for the Life and Beauty of the World" (2012). Aos elementos projetuais em questão, Alexander deu o título de padrões e somam 253, descritos e justificados em "Uma Linguagem de Padrões", como parâmetros a serem utilizados nos processos de projeto de edificações, áreas externas e comunidades. Este montante de padrões subdividese em temáticas específicas, basicamente definidas por escalas projetuais como região, cidades, bairros, áreas comuns externas e o edifício.

Observa-se um curioso "contraste" entre as teorias fundamentadas por Alexander e os métodos implementados por ele, como foi o caso da 
Linguagem de Padrões. Afinal, doze anos antes de lançar este livro, o arquiteto publicou o texto "A City is not a Tree" (1965), focalizando sua crítica na visão dos arquitetos modernistas sobre as cidades. Naquele momento, Christopher Alexander discutira que esses profissionais tratavam as cidades como árvores e, portanto, as projetavam com estruturas artificiais ou em rede. Assim sendo, podiam dispor de diretrizes puramente funcionais para essas cidades, determinando suas características de modo impositivo.

Para Alexander, as cidades deveriam ser reconhecidas enquanto espaços "naturais", providos de morfologia, uso e ocupação do solo, oriundos de manifestações espontâneas, impressas na paisagem por seus habitantes, ao longo de suas vidas. Semelhante postura este arquiteto assumira em outra produção de sua autoria: "The Oregon Experiment" (1975), livro que contextualiza sua intervenção na reformulação do campus da Universidade de Oregon, em Eugene/EUA. Ao comentar os pressupostos do processo participativo desenvolvido por ele e sua equipe nesse campus, explicita o "Princípio do Crescimento Orgânico" que, resumidamente, implica em uma expansão de ambientes e atividades no local, a partir das necessidades que surgem ao longo da vida da Universidade, em vez de um crescimento rígido, calcado em Planos de Expansão.

Eis, portanto, o "contraste": o crescimento espontâneo, o reconhecimento das características vernaculares do sítio urbano são algo preconizado por Alexander e, por outro lado, o arquiteto sugere uma perspectiva universalista que busca a unificação de conceitos em "parâmetros de projeto". Seriam justificativas para este contraste: a "flexibilidade" de adaptação da Linguagem de Padrões a diferentes processos, uma vez que se selecionam as diretrizes que melhor expressam a realidade de uma comunidade, ou o fato destes parâmetros de projeto terem sido construídos a partir de experiências concretas e com a participação de usuários?

Segundo Stephen Grabow, a concepção da Linguagem por Alexander e seus parceiros arquitetos do CES permitiu a ele identificar três níveis de entendimento desta tarefa: o primeiro de que, através da teoria implementada, as pessoas usariam a Linguagem para produzir o ambiente por elas mesmas, compartilhando-o; 2. o sentido que cada pessoa possui sobre como os edifícios concebidos, a partir da Linguagem de Padrões, poderiam ser realmente belos; 3. a famosa "qualidade" que, segundo Alexander, fora profundamente compreendida, principalmente, por Sara Ishikawa e Ingrid Fiksdahl-King, colaboradoras do livro " $A$ Pattern Language".

Os duzentos e cinquenta e três padrões arrolados no livro qualificam a concepção dos espaços regionais, de vizinhança e dos edifícios, em alguns casos, com alguma peculiaridade inovadora como: "núcleos excêntricos (padrão 28)" que atendem a diferentes densidades nos centros urbanos; "corrente de projetos comunitários (padrão 45)" configurando um anel contínuo de serviços e atividades ao redor de um centro de lazer da comunidade.

Todavia, na Linguagem de Padrões, Alexander rediscute elementos presentes em outros movimentos urbanísticos, por exemplo: "área externa coletiva (padrão 67)" semelhante aos espaços comuns das Cidades Jardins; a "rua de pedestres (padrão 100)" também identificada em projetos de cidades utópicas e, inclusive, nas produções modernas do início do século XX, cujas ideias foram amplamente criticadas por ele. É oportuno mencionar, que muitos destes padrões inspiraram concepções urbanísticas posteriores à obra "A Pattern Language", como os projetos de vizinhanças do New Urbanism, movimento que reconfigurou cidades norte-americanas na década de 1990.

Cotejando-se as edições em inglês e português de "A Pattern Language", é possível concluir que há similaridade na estrutura e conteúdo do livro, com o emprego correto da terminologia concebida pelos autores para os 253 padrões. Consequentemente, considera-se que esta tradução tornará a obra mais acessível, contemplando pesquisas científicas e outros estudos brasileiros sobre a obra de Christopher Alexander. 